\title{
Outcomes and patterns of care of patients with locally advanced oropharyngeal carcinoma treated in the early $21^{\text {st }}$ century
}

\author{
Adam S Garden ${ }^{1 *}$, Merrill S Kies², William H Morrison', Randal S Weber³, Steven J Frank', Bonnie S Glisson², \\ Gary B Gunn ${ }^{1}$, Beth M Beadle ${ }^{1}$, K Kian Ang ${ }^{1}$, David I Rosenthal ${ }^{1}$ and Erich M Sturgis 3,4
}

\begin{abstract}
Background: We performed this study to assess outcomes of patients with oropharyngeal cancer treated with modern therapy approaches.

Methods: Demographics, treatments and outcomes of patients diagnosed with Stage 3-4B squamous carcinoma of the oropharynx, between 2000 - 2007 were tabulated and analyzed.

Results: The cohort consisted of 1046 patients. The 5- year actuarial overall survival, recurrence-free survival and local-regional control rates for the entire cohort were $78 \%, 77 \%$ and $87 \%$ respectively. More advanced disease, increasing T-stage and smoking were associated with higher rates of local-regional recurrence and poorer survival.

Conclusions: Patients with locally advanced oropharyngeal cancer have a relatively high survival rate. Patients' demographics and primary tumor volume were very influential on these favorable outcomes. In particular, patients with small primary tumors did very well even when treatment was not intensified with the addition of chemotherapy.
\end{abstract}

Keywords: Radiation, Oropharyngeal cancer, IMRT, Chemoradiation, Squamous cell

\section{Introduction}

During the latter part of the $20^{\text {th }}$ century, several changes occurred in the management and epidemiology of head and neck cancer. Numerous trials were conducted investigating intensification of therapy. One avenue of investigation was altered fractionation of radiation schedules. Multiple trials demonstrated a benefit to mildly accelerating radiation schedules, or hyperfractionating radiation [1-3]. Incorporation of chemotherapy to improve disease control and allow for organ preservation was studied extensively during 1980 - 2000 [4]. Concomitant chemotherapy and radiation has become established as a standard of non-surgical care for patients with locally advanced disease. Sequential induction chemotherapy followed by definitive radiotherapy, with or without concomitant chemotherapy, remains under study; however, there has

\footnotetext{
* Correspondence: agarden@mdanderson.org

'Department of Radiation Oncology, University of Texas M.D. Anderson

Cancer Center, 1515 Holcombe Blvd, Houston, TX 77030, USA

Full list of author information is available at the end of the article
}

been FDA approval for use of docetaxel, cisplatin and fluorouracil (TPF) as an induction regimen in selected patients [5].

Intensity-modulated radiation therapy (IMRT) also was developed during the last decade of the $20^{\text {th }}$ century. IMRT is a system of radiation treatment planning and delivery that allows for more optimal radiation dose distributions. Favorable early reports published in the first few years of the past decade [6-8] led to the incorporation of IMRT into many cooperative group trials, and there has been a striking increase between 2000-2010 in the use of IMRT as a routine therapy for head and neck cancer [9].

These changes in management have paralleled a change in the epidemiology of head and neck cancer in the past 2 decades, and particularly oropharyngeal cancer. There has been a dramatic increase in the incidence of oropharyngeal cancer particularly among middle-aged white men [10]. With declining smoking prevalence over this timeframe, the phenomenon of rising oropharyngeal cancer incidence has been attributed to the prevalence of oropharyngeal 
cancer associated with human papillomavirus (HPV) $[11,12]$. Retrospective series and, more recently, secondary analyses of prospective clinical trials have demonstrated better prognoses for patients with HPV positive disease compared with similarly treated patients who are HPV negative [13-15].

In tandem with the therapeutic advances described above, we progressively intensified therapy for patients with oropharyngeal carcinoma, though we often attempted to use a risk based approach [16] that incorporated disease volume and location rather than uniformly deliver identical therapy for all stage 3 and 4 patients. Previous reports from our group suggested that patients with multiple nodes or nodal disease in levels 3 and 4 had a greater risk of developing distant disease [17]. In general, we favored neoadjuvant therapy for these patients in attempt to reduce distant metastasis risk. Decisions for adding concurrent chemotherapy were based more often on T-category, with higher staged patients treated with greater therapy intensification. As our management approach evolved, we observed demographic changes in our patients similar to those occurring on a national level. This study was conducted to assess our patients' outcomes and determine what factors were the most influential.

\section{Methods}

The database maintained by the Department of Radiation Oncology at The University of Texas M.D. Anderson Cancer Center (MDACC) was searched to identify patients irradiated for oropharyngeal carcinoma (squamous cell, poorly differentiated or undifferentiated, or not otherwise specified) between the years 2000-2007. Our institutional review board granted permission to conduct this retrospective study.

The search identified 1162 medical records. Patients were excluded for the following reasons: distant metastases or concurrent malignancies (exclusive of a second malignancy of the oropharynx) at the time of diagnosis (16 patients), a previously treated malignancy of the head and neck or previous radiation to the head or neck (8), a history of any malignancy (excluding non-melanomatous skin cancer) within two years of diagnosis (7), or treatment with chemotherapy prior to staging at MDACC (8). In addition 69 patients who did not meet the staging criteria of interest (Stage 3-4B), and 8 patients with poor performance statuses, staged $4 \mathrm{~B}$, and treated with palliative intent were excluded. One thousand forty-six patients formed the cohort for analysis.

Medical records were reviewed to assess patients' demographic, clinical, radiologic and pathologic data. Based upon the medical history at presentation and as described previously [18] patients were classified as current smokers, former smokers, or never-smokers. Smokers were further evaluated to assess if they quit smoking, or continued to smoke during or subsequent to treatment.

Patients' disease was staged according to the AJCC 2002 staging system [19]. Charts were reviewed to verify tumor size and sites of invasion. Staging variables of interest included T-category, N-category, and overall AJCC group stage. Patients staged Tx were typically those seen posttonsillectomy and if the tumor size could not be determined after record review, these patients were staged T1 for the purpose of AJCC stage grouping in this analysis. Those staged $\mathrm{Nx}$ were patients in whom a solitary node was excised for diagnosis, and size could not be determined. These patients were coded as N1 for the purpose of this analysis.

Chi-squared tests were used to compare proportions between subsets. The t-test was used for comparison of means. The Kaplan-Meier method was used to calculate actuarial curves. Time of diagnosis was used as time zero. Comparisons between survival curves were made using the log-rank test. Multivariate analysis was performed using the Cox proportional model.

Our approach has been to perform neck dissection only in patients with suspected residual disease following radiation. During the years of this study reassessment principally consisted of physical examination and CT scan 6 to 8 weeks after radiation. Those patients with an obvious residual mass were operated. Patients with questionable residual disease had sonograms with aspiration performed to try to resolve whether there was viable disease. Routine use of positron-emission tomography had not become a routine practice during the years of this study. Details of our experience with regards to management of the neck in an overlapping cohort has been recently described [20]. Patients who had neck dissections performed within 6 months of radiation for suspected residual disease were not scored as having disease recurrence.

\section{Results}

\section{Demographics and staging}

Table 1 details the $\mathrm{T}$ and $\mathrm{N}$ stages of the 1046 patients. Despite having "locally advanced" head and neck cancer, $62 \%$ of patients had T1-T2 tumors. Identification as having stage 3-4B disease was often based on the presence of nodal disease, as only $5 \%$ of patients were node negative.

Patients' demographics, tumor sites and staging are detailed in Table 2. Never smokers comprised $41 \%$ of the cohort. Former smokers had quit $1-53$ years prior to diagnosis (median, 18 years). Among all smokers, the median and mean pack years were 30 and 34 , though there was a difference between former and current smokers, with mean pack years of 27 and 45, respectively. Thirtyone percent of former smokers, $56 \%$ of current smokers who quit at diagnosis, and $78 \%$ of smokers who continued to smoke had $>30$ pack year history at diagnosis $(\mathrm{p}<.001)$. 
Table $1 \mathrm{~T}$ and N stages of 1046 patients with stage 3- 4b oropharyngeal cancer

\begin{tabular}{|c|c|c|c|c|c|c|c|c|}
\hline & \multicolumn{6}{|c|}{$\mathrm{N}$-category } & \multirow[t]{2}{*}{ Total } \\
\hline & & 0 & 1 & $2 a$ & $2 b$ & $2 c$ & 3 & \\
\hline \multirow[t]{5}{*}{ T-category } & 1 & 0 & 81 & 69 & 118 & 26 & 22 & 316 \\
\hline & 2 & 0 & 59 & 47 & 134 & 53 & 31 & 324 \\
\hline & 3 & 37 & 30 & 6 & 81 & 46 & 19 & 219 \\
\hline & $4 \mathrm{~A}$ & 13 & 18 & 3 & 36 & 59 & 17 & 146 \\
\hline & $4 \mathrm{~B}$ & 7 & 4 & 0 & 10 & 10 & 10 & 41 \\
\hline Total & & 57 & 192 & 125 & 379 & 194 & 99 & 1046 \\
\hline
\end{tabular}

The tonsil and base of tongue were the most common primary sites. Tonsil and base of tongue primary sites accounted for only $85 \%$ of current smoking patients compared with $94 \%$ and $96 \%$ for former and never smokers, respectively $(\mathrm{p}<.001)$. There were also significant differences among the stages of the 3 smoking groups. The overall group staging was different among the smoking groups as Stage 4B was most common among current smokers $(\mathrm{p}<.001)$. Never smokers had a greater proportion of smaller primary tumors $(71 \%, \mathrm{~T} 1-2)$ compared with former smokers (62\%, T1-2), and current smokers (44\%, T1-T2). Differences in N-category among the 3 smoking groups were not statistically significant, though the trends observed were for never smokers to have a higher proportion of N1-2c patients and current smokers to have a higher proportion of $\mathrm{N} 0$ and $\mathrm{N} 3$ patients.

Nodal location correlated with nodal stage. Only $4 \%$ of patients with stage N1-2a had nodes in levels 3 or 4 compared with $51 \%$ of patients staged N2b-2c and $82 \%$ of patients staged N3.

The primary site of tumor also correlated with stage. Only $26 \%$ of patients with non-tonsil, non -base of tongue cancers had stage T1-or T2 disease. Limiting comparisons to the tonsil and base of tongue, there were differences between these 2 sites as well. Patients with base of tongue cancer were more likely to present with $\mathrm{T} 4$ primaries (20\%) compared to those with tonsillar cancer (12\%). Stage N0 was more common among patients with nontonsil / non-base of tongue primaries (22\%) than for those with cancers of the tonsil (5\%) or base of tongue (4\%). Stage N2c was also more common for patients with base of tongue cancer $(24 \%)$ than for patients with tonsillar cancer (13\%).

\section{Therapy}

All patients had their cases discussed at a weekly multidisciplinary clinic and recommendations for therapy as well as assessment for treatment on protocol were made. During these years, we had participated in numerous therapy trials, and 210 patients in this cohort were treated on trial. Among the trials were 4 RTOG trials $[8,13,21,22]$, the multiinstitutional phase III cetuximab trial [23] and 2 inhouse phase I-II trials [16,24]. Final treatment decisions were made with the patient and their physicians. Pre-therapy gastrostomies were not mandated prior to therapy, and gastrostomy placement during therapy was individualized based on the clinical scenario.

IMRT was used to treat $69 \%$ of our patients. Figure 1 shows the use of IMRT over the years of study, as we began to incorporate IMRT into our practice in 2000; by 2006, it was used exclusively for our patients. While IMRT was more commonly used in never smokers, during the early 2000s many patients with T3 and T4 tumors were enrolled on studies not allowing the use of IMRT. Seven hundred patients were treated with once daily fractionation. The median dose was 70 Gy $(2.2-75$ Gy). Fourteen patients (1\%) received less than $60 \mathrm{~Gy}$. Nine of these 14 patients chose to discontinue treatment, 2 had treatment stopped due to toxicity and 3 died during therapy. The median number of fractions was $33(1-44)$. Ipsilateral therapy was used to treat 66 patients $(6 \%)$ with welllateralized tonsillar cancer.

Systemic therapy was used in 645 patients (62\%). Concurrent therapy was delivered to 513 patients (49\%). Cisplatin was the most common concurrent drug (344 patients), followed by carboplatin (100 patients), and cetuximab (74 patients); 103 patients were treated with multidrug regimens. Two hundred forty-two (23\%) patients were treated with neoadjuvant chemotherapy. All neoadjuvant regimens were platin and taxane based. One hundred twenty-four patients received both neoadjuvant and concurrent chemotherapy. There were no differences between delivering either concurrent or induction chemotherapy when grouped by smoking status. There were differences in the use of chemotherapy based on staging. The use of concurrent chemotherapy increased incrementally with T-category, as 14\%, 39\%, 80\% and $90 \%$ of patients with $\mathrm{T} 1, \mathrm{~T} 2, \mathrm{~T} 3, \mathrm{~T} 4$, respectively received concurrent chemotherapy. Induction therapy was more commonly used among patients with advanced nodal disease, as $34 \%$ of patients with $\mathrm{N} 2 \mathrm{~b}-\mathrm{N} 3$ disease were treated with neoadjuvant therapy compared with only $5 \%$ of patients staged NO - N2a. There was no difference in the use of induction chemotherapy based on T-category, as $23 \%$ and $23 \%$ of patients with T1-2 disease and T3-4 disease received neoadjuvant chemotherapy. Overall, $44 \%$ of patients with T1-2 disease received chemotherapy compared to $89 \%$ of patients with T3-4 disease.

Ninety-six patients had tonsillectomies prior to therapy. All 96 presented with lymphadenopathy. Twenty-eight of these 96 patients had tonsillectomies performed as part of their diagnostic staging procedures at MDACC. The remaining 68 presented to MDACC following tonsillectomy. Only one of these 68 patients had a tonsillectomy done as a therapeutic procedure for known malignancy. 
Table 2 Patient demographics and treatment

\begin{tabular}{|c|c|c|c|c|c|}
\hline & $\begin{array}{c}\text { All }(N=1046) \\
\text { No. }(\%)\end{array}$ & $\begin{array}{l}\text { Current smokers } \\
(N=242) \text { No. }(\%)\end{array}$ & $\begin{array}{l}\text { Former smokers } \\
(N=381) \text { No. }(\%)\end{array}$ & $\begin{array}{c}\text { Never smokers } \\
(N=423) \text { No. }(\%)\end{array}$ & $p$-value \\
\hline \multicolumn{6}{|l|}{ Age in years } \\
\hline Mean (range) & $56.2(28-87)$ & $55.6(35-80)$ & $59.3(36-87)$ & $53.7(28-81)$ & .01 \\
\hline Median & 55 & 55 & 58 & 53 & \\
\hline Sex & & & & & .725 \\
\hline Male & $906(87)$ & $207(86)$ & $334(88)$ & $365(86)$ & \\
\hline Female & $140(13)$ & $35(14)$ & $47(12)$ & $58(14)$ & \\
\hline Race & & & & & $<.001$ \\
\hline White & $930(89)$ & $197(21)$ & $353(38)$ & $380(41)$ & \\
\hline Black & $47(5)$ & $29(62)$ & $3(6)$ & $15(32)$ & \\
\hline Hispanic & $55(5)$ & $12(22)$ & $19(35)$ & $24(44)$ & \\
\hline Other & $14(1)$ & $5(36)$ & $6(43)$ & $3(21)$ & \\
\hline Cigarette pack-year & & & & & $<.001$ \\
\hline None & $423(42)$ & & & $423(100)$ & \\
\hline $1-30$ & $339(32)$ & $86(36)$ & $253(69)$ & & \\
\hline$>30$ & $265(26)$ & $153(64)$ & $112(31)$ & & \\
\hline Primary site & & & & & $<.001$ \\
\hline Tonsil & $460(44)$ & $111(46)$ & $171(45)$ & $178(42)$ & \\
\hline Base of tongue & $511(49)$ & $95(39)$ & $186(49)$ & $230(54)$ & \\
\hline Other* & $75(7)$ & $36(15)$ & $24(6)$ & $15(4)$ & \\
\hline T-category & & & & & $<.001$ \\
\hline $1-2$ & $640(62)$ & $107(44)$ & $235(62)$ & $298(71)$ & \\
\hline $3-4$ & $406(38)$ & $135(56)$ & $146(38)$ & $125(30)$ & \\
\hline N-category & & & & & .07 \\
\hline 0 & $57(5)$ & $20(8)$ & $22(6)$ & $15(4)$ & \\
\hline $1-2 a$ & $317(30)$ & $63(26)$ & $120(31)$ & $134(32)$ & \\
\hline $2 b-2 c$ & $573(55)$ & $128(53)$ & $205(54)$ & $240(57)$ & \\
\hline 3 & $99(9)$ & $31(13)$ & $34(9)$ & $34(8)$ & \\
\hline Stage & & & & & .001 \\
\hline 3 & $206(20)$ & $43(18)$ & $83(22)$ & $80(19)$ & \\
\hline $4 \mathrm{~A}$ & 707 (68) & $149(62)$ & $257(68)$ & $30(72)$ & \\
\hline $4 \mathrm{~B}$ & $133(13)$ & $50(21)$ & $41(11)$ & $42(10)$ & \\
\hline Treatment & & & & & .176 \\
\hline XRT alone & $415(40)$ & $83(34)$ & $158(42)$ & $175(41)$ & \\
\hline CTXRT & $389(37)$ & $102(43)$ & $146(38)$ & $141(33)$ & \\
\hline Ind. $C T X>X R T$ & $118(11)$ & $29(12)$ & $35(9)$ & $53(13)$ & \\
\hline Ind. CTX > CTXRT & $124(12)$ & $28(12)$ & $42(11)$ & $54(14)$ & \\
\hline Radiation technique & & & & & $<.001$ \\
\hline IMRT & $714(69)$ & $141(58)$ & $211(69)$ & $316(75)$ & \\
\hline 3D conformal & $328(31)$ & $101(42)$ & $120(31)$ & $107(25)$ & \\
\hline Radiation Fractionation & & & & & .442 \\
\hline Once- daily & $700(67)$ & $154(64)$ & $250(66)$ & $296(70)$ & \\
\hline Altered fractionation & $346(33)$ & $88(36)$ & $131(34)$ & $127(30)$ & \\
\hline
\end{tabular}

*Other primary sites: soft palate, 19 patients; pharyngeal wall, 34, NOS (not otherwise specified), 22. XRT - Radiotherapy; CTXRT - concurrent chemoradiation; Ind. CTX - Induction chemotherapy. 


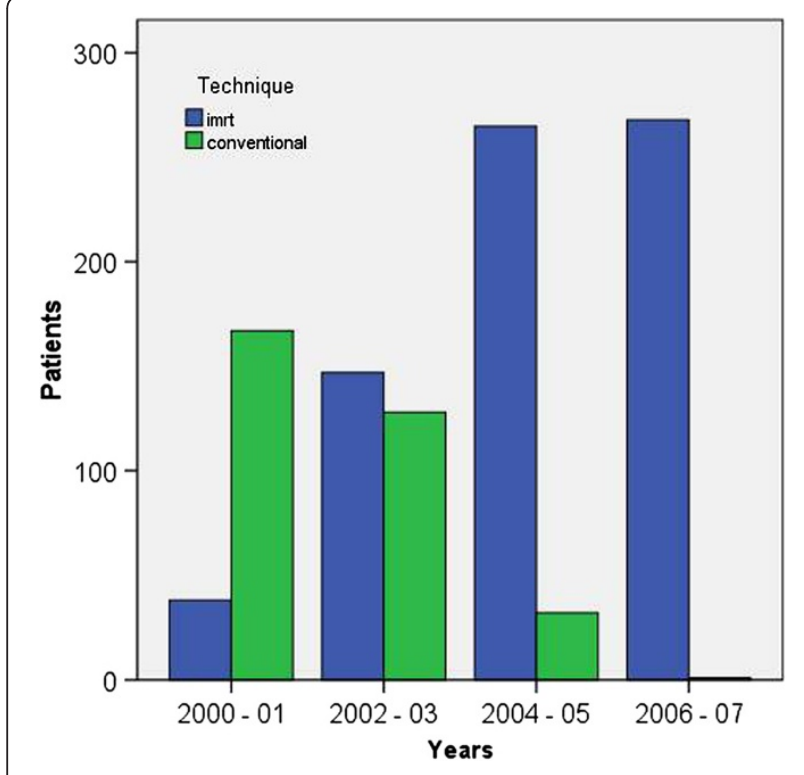

Figure 1 Number of patients treated with conventional radiation techniques and intensity-modulated radiation (IMRT).

An additional 8 patients had excisions of their primary disease, and 3 had more comprehensive surgery on their primary tumor. Fifty-five patients had neck dissections and 88 had excisional biopsies of nodal disease prior to therapy. A total of 44 patients (4\%) presented without obvious disease at both the primary site and neck.

Post-radiation neck dissections were performed in 253 patients; 64 patients (25\%) had pathologic residual disease in their neck dissection specimens.

\section{Outcomes}

The median follow-up time was 58 months (range, 1 130 months). Only 15 of 801 patients (2\%) alive at last contact had less than 2 years of follow-up. The actuarial 5-year overall survival rate was 78\% (95\% CI, 75 - 81\%).

Overall, 234 patients had disease recurrence, resulting in a 5-year recurrence free survival rate of $77 \%$ (95\% CI, $74-80 \%)$. The 5 -year local-regional control rate was $87 \%$ (95\% CI, $85-89 \%)$, as 135 patients had disease recur at the primary site or in the neck (52 at the primary site, 35 in the neck, and 48 in both the primary and neck). The 5 - year actuarial overall survival for patients with localregional recurrence was $22 \%$ (95\% CI, $15-30 \%)$.

The 5-year distant recurrence rate in patients who did not have local regional recurrence was $11 \%$ (95\% CI, $9-13 \%)$.

Forty-five (5\%) of patients with local regional control had a gastrostomy at last follow-up. Five of these patients also had tracheostomies. Increasing stage (both $\mathrm{T}$ and $\mathrm{N}$ ), altered fractionation, conventional radiation technique, and concurrent chemoradiation were all associated with an increased rate of gastrostomy (Table 3, univariate analysis).

\section{Analysis of variables of interest}

Primary site, smoking status, T-category, and radiation technique were all associated in multivariate analysis with local-regional control (Table 4). The crude local regional control rates for patients grouped by primary site were: tonsil $92 \%$, base of tongue $86 \%$, and other sites $68 \%$. The 3 other variables were strongly correlated with each other. Eighty-one percent of patients with T1-2 disease were treated with IMRT, compared with $49 \%$ of patients with T3-4 disease; $75 \%$ of never smokers were treated with IMRT compared with $58 \%$ of current smokers; and $70 \%$ of never smokers had T1-2 disease, compared with $44 \%$ of current smokers.

The 5-year local-regional control rates were $75 \%, 88 \%$, and $92 \%$ for current smokers, former smokers, and never smokers, respectively (Figure 2a). Among current smokers, the 5-year actuarial local regional control rates were $78 \%$ and $67 \%(\mathrm{p}=.08)$ for those who quit smoking versus

Table 3 Gastrostomy rates at last contact for patients with local-regional control

\begin{tabular}{|c|c|c|c|}
\hline Variable & $\begin{array}{l}\text { Patient } \\
\text { number }\end{array}$ & $\begin{array}{l}\text { Gastrostomy at } \\
\text { last follow-up }\end{array}$ & $\begin{array}{l}p \text {-value (chi- } \\
\text { squared test) }\end{array}$ \\
\hline T-stage & & & $<.01$ \\
\hline $1-2$ & 604 & $2 \%$ & \\
\hline $3-4$ & 307 & $10 \%$ & \\
\hline $\mathrm{N}$-stage & & & $<.01$ \\
\hline $0-2 a$ & 338 & $3 \%$ & \\
\hline $2 b-2 c$ & 492 & $5 \%$ & \\
\hline 3 & 81 & $11 \%$ & \\
\hline IMRT & & & $<.01$ \\
\hline Yes & 657 & $3 \%$ & \\
\hline No & 254 & $9 \%$ & \\
\hline Fractionation & & & $<.01$ \\
\hline Conventional & 630 & $4 \%$ & \\
\hline Altered & 281 & $8 \%$ & \\
\hline $\begin{array}{l}\text { Induction } \\
\text { Chemotherapy }\end{array}$ & & & .03 \\
\hline Yes & 208 & $2 \%$ & \\
\hline No & 703 & $6 \%$ & \\
\hline $\begin{array}{l}\text { Concurrent } \\
\text { Chemoradiation }\end{array}$ & & & $<.01$ \\
\hline Yes & 422 & $7 \%$ & \\
\hline No & 489 & $3 \%$ & \\
\hline Smoking & & & .4 \\
\hline Current & 184 & $3 \%$ & \\
\hline Former & 338 & $5 \%$ & \\
\hline Never & 389 & $5 \%$ & \\
\hline
\end{tabular}


Table 4 Local-regional control and survival

\begin{tabular}{|c|c|c|c|c|}
\hline & $\begin{array}{c}5 \text {-year local- } \\
\text { regional control }\end{array}$ & $p$-value* & $\begin{array}{c}\text { 5-year } \\
\text { overall } \\
\text { survival }\end{array}$ & $p$-value ${ }^{*}$ \\
\hline \multicolumn{5}{|l|}{ Age in years } \\
\hline $\begin{array}{l}\text { Continuous } \\
\text { variable }\end{array}$ & & .136 & & $<.001$ \\
\hline Sex & & .896 & & .438 \\
\hline Male & $87 \%$ & & $79 \%$ & \\
\hline Female & $87 \%$ & & $77 \%$ & \\
\hline Race & & .091 & & .261 \\
\hline White & $88 \%$ & & $81 \%$ & \\
\hline Non-white & $76 \%$ & & $62 \%$ & \\
\hline Smoke & & .002 & & $<.001$ \\
\hline Current & $75 \%$ & & $60 \%$ & \\
\hline Former & $88 \%$ & & $80 \%$ & \\
\hline Never & $92 \%$ & & $88 \%$ & \\
\hline Primary site & & .006 & & $<.001$ \\
\hline Tonsil & $91 \%$ & & $83 \%$ & \\
\hline $\begin{array}{l}\text { Base of } \\
\text { tongue }\end{array}$ & $86 \%$ & & $80 \%$ & \\
\hline Other & $65 \%$ & & $43 \%$ & \\
\hline T-category & & $<.001$ & & $<.001$ \\
\hline $1-2$ & $94 \%$ & & $90 \%$ & \\
\hline $3-4$ & $75 \%$ & & $60 \%$ & \\
\hline N-category & & .446 & & .001 \\
\hline 0 & $74 \%$ & & $65 \%$ & \\
\hline $1-2 a$ & $93 \%$ & & $86 \%$ & \\
\hline $2 b-2 c$ & $86 \%$ & & $79 \%$ & \\
\hline 3 & $80 \%$ & & $59 \%$ & \\
\hline $\begin{array}{l}\text { Lowest neck } \\
\text { level }\end{array}$ & & .529 & & .498 \\
\hline 0 & $74 \%$ & & $67 \%$ & \\
\hline 2 & $90 \%$ & & $83 \%$ & \\
\hline 3 & $86 \%$ & & $77 \%$ & \\
\hline 4 & $76 \%$ & & $67 \%$ & \\
\hline Treatment & & .454 & & .027 \\
\hline XRT alone & $92 \%$ & & $86 \%$ & \\
\hline CTXRT & $82 \%$ & & $72 \%$ & \\
\hline $\begin{array}{l}\text { Ind. CTX > } \\
\text { XRT }\end{array}$ & $89 \%$ & & $84 \%$ & \\
\hline $\begin{array}{l}\text { Ind. } C T X> \\
\text { CTXRT }\end{array}$ & $81 \%$ & & $71 \%$ & \\
\hline $\begin{array}{l}\text { Radiation } \\
\text { technique }\end{array}$ & & .003 & & .084 \\
\hline IMRT & $92 \%$ & & $84 \%$ & \\
\hline $\begin{array}{l}\text { 3D } \\
\text { conformal }\end{array}$ & $77 \%$ & & $66 \%$ & \\
\hline
\end{tabular}

Table 4 Local-regional control and survival (Continued)

\begin{tabular}{lccc}
\hline Radiation & .414 & .150 \\
Fractionation \\
$\begin{array}{l}\text { Once- daily } \\
\text { Altered }\end{array}$ & $90 \%$ & $83 \%$ & \\
fractionation & $81 \%$ & $70 \%$ & \\
*multivariable analysis; XRT - Radiotherapy; CTXRT - concurrent \\
chemoradiation; Ind. CTX - Induction chemotherapy.
\end{tabular}

those who continued to smoke. While the number of years former smokers had quit and the number of packyear among all smokers were both tested as continuous variables, only pack-year was significant. Evaluating smoking intensity (pack-year number) as a categorical variable (Figure 2b), the 5-year actuarial local-regional control rates were: zero pack-year, 92\%, 1 - 30 pack-year, $89 \%$, $>30$ pack year, $75 \%$ ( $\mathrm{p}=.064$ in multivariate analysis). Among current smokers, a lower smoking intensity was associated with quitting, as $44 \%$ of smokers who quit at diagnosis had 1-30 pack-year history, compared with only $27 \%$ of those who continued to smoke.

The 5-year actuarial local-regional control rates for patients grouped by T-category were 96\%, 93\%, 85\%, 65\%, and 59\% for stages T1, T2, T3, T4a and T4b, respectively

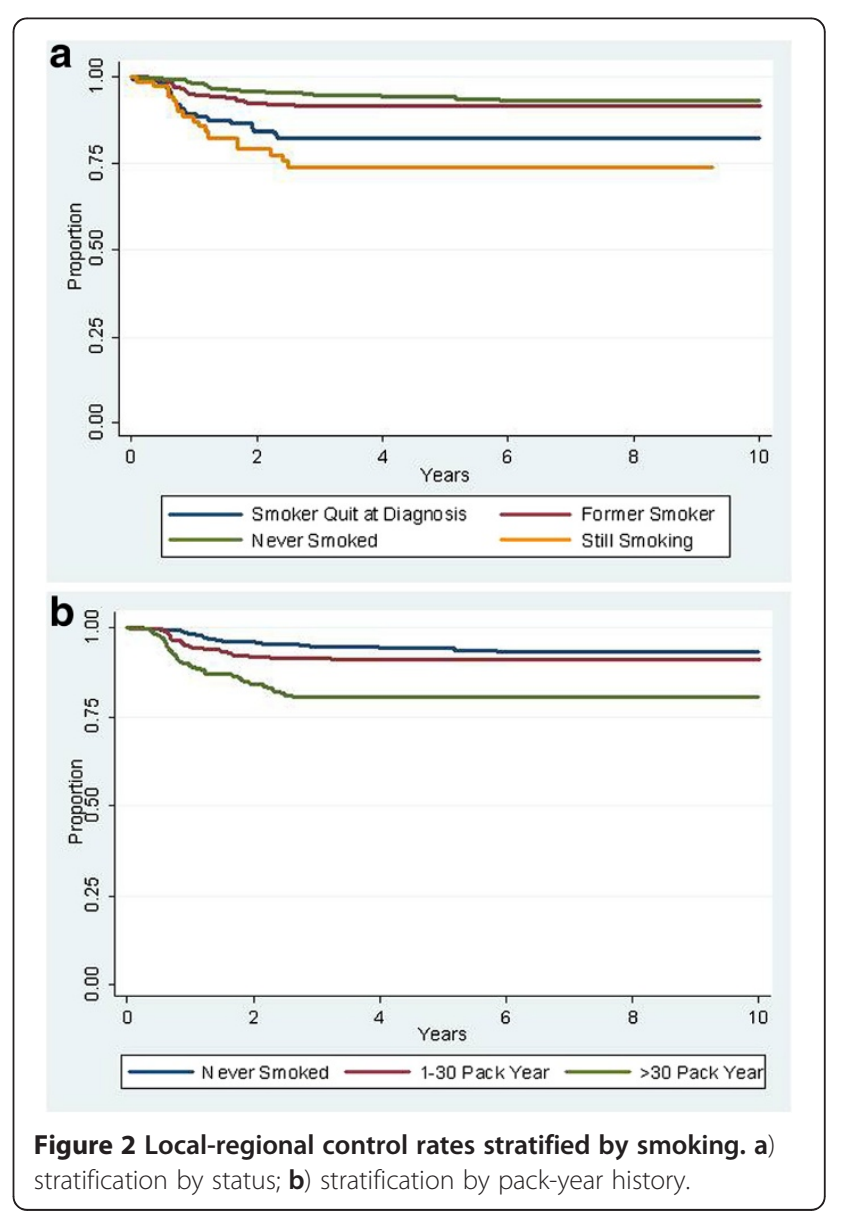


(Figure 3). Differences were significant for the overall grouping, as well as for all paired comparisons except T1 vs. T2 and T4a vs. T4b.

The only treatment factor statistically significant for an association with local-regional control, was radiation treatment technique as those treated with IMRT had a 91\% 5 -year rate of local-regional control compared to $77 \%$ for patients treated with conventional techniques. However, significant confounding by T-stage exists. Subgrouping patients by T-category, the differences in local-regional control were only seen in patients staged T4, as those treated with IMRT had a 5-year control rate of 77\% compared to $51 \%$ for those treated with conventional techniques.

The use of concurrent chemotherapy was not associated with improved local-regional control. However in subgroup analysis, (Figure 4), patients with T3-4 disease who were treated with concurrent chemotherapy had a 5-year actuarial rate of local-regional control of $77 \%$ compared with $63 \%$ for those who did not receive concurrent chemotherapy $(\mathrm{p}=.01)$. Amongst patients with $\mathrm{T} 1-2$ disease, the 5 -year actuarial rate of local-regional control was $91 \%$ for those treated with concurrent chemotherapy compared with 95\% for those who did not receive concurrent chemotherapy $(\mathrm{p}=.06)$. In pairwise comparisons of concurrent single agent cisplatin, carboplatin and cetuximab, we did not find statistically significant differences in local-regional control.

$\mathrm{N}$-category was not associated with local recurrence, but was associated with regional recurrence. The 5-year actuarial regional control rates were $96 \%, 90 \%$, and $83 \%$ for stages N0-2a, N2b-c and N3, respectively. In multivariate analysis, disease recurrence in the neck (limited to patients with local control) was associated with nodal level, as regional control rates were progressively worse for patients with disease in levels 2,3 , and 4, respectively.

We further explored the interactions of T1-2 disease with $\mathrm{N}$-category and chemotherapy on local-regional

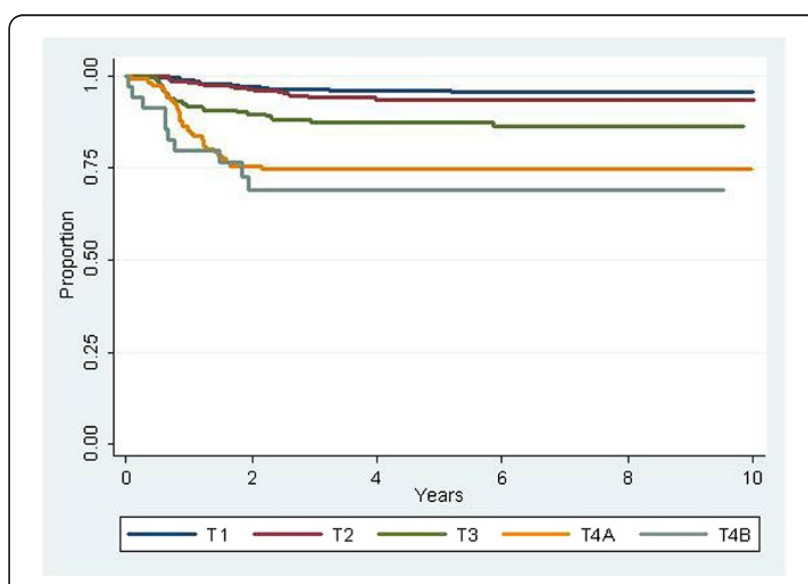

Figure 3 Local-regional control rates stratified by T-category.

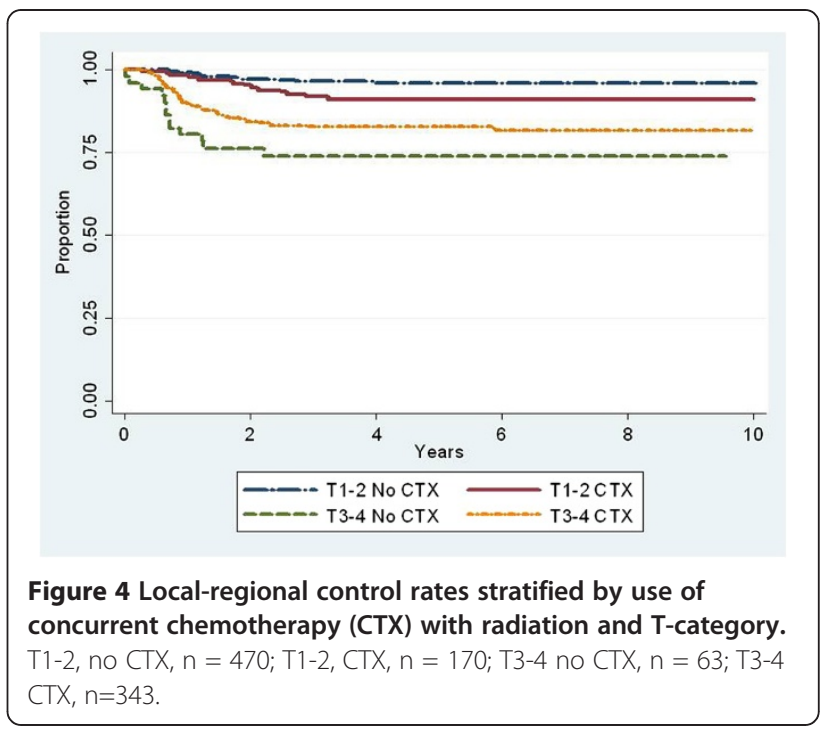

control, dichotimizing N-category into N1-2a and N2b-3. Thirty-nine (15\%) T1-2, N1-2a patients, and 230 of T1-2, N2b-3 patients (60\%) received chemotherapy (Table 5). No statistical improvement in local-regional control was seen for any of the groups who received chemotherapy, nor was any benefit seen when further subgrouped by induction or concurrent delivery.

Analysis of distant failure restricted to patients with local-regional control revealed a higher metastasis rate seen with increasing age, higher T-category and lower neck levels. The 5 -year distant failure rates were $7 \%, 16 \%$ and $25 \%$ for patients with disease in neck levels 2,3 and 4 , respectively. The 5 -year distant failure rate for node negative patients was $13 \%$. The 5 -year distant failure rates for patients treated with and without induction chemotherapy were $13 \%$ and $11 \%$, respectively ( $p=.636$ ). Further subgroup analysis of patients staged $\mathrm{N} 2 \mathrm{~b}-3$ also showed no difference in distant failure rates for patients treated with and without induction chemotherapy $(\mathrm{p}=.642)$.

Multiple variables were statistically associated with survival (Table 4). N-category was associated with survival outcomes, but not in an orderly pattern, as patients with N2a disease had the best outcomes, and node negative patients did not have a higher survival rate than patients who were node positive. Current smokers, older patients, advanced T-category, primary site not in the tonsil or base of tongue, and the use of concurrent chemotherapy were associated with decreasing survival. The 5-year survival rates for patients treated with and without concurrent chemotherapy were $71 \%$ and $85 \%$, respectively. Among patients with T1-T2 disease, the 5-year survival rates were $90 \%$ and $90 \%$ ( $\mathrm{p}=.42$ ) for those treated with and without concurrent chemotherapy, and for patients with T3-T4 disease the 5-year survival rates were $63 \%$ and $42 \%(\mathrm{p}<.01)$ for those treated with and without concurrent chemotherapy. 
Table 5 Local-regional control in patients with T1-2 disease dichotomized by N-category

\begin{tabular}{|c|c|c|c|c|}
\hline & \multicolumn{2}{|c|}{ T1-2, N1-2a } & \multicolumn{2}{|c|}{ T1-2, N2b-c } \\
\hline & Patient number & 5-year local-regional control & Patient number & 5-year local-regional control \\
\hline \multicolumn{5}{|l|}{ Treatment } \\
\hline XRT alone & 217 & $98 \%$ & 154 & $92 \%$ \\
\hline CTXRT & 32 & $90 \%$ & 87 & $90 \%$ \\
\hline Ind. $C T X>X R T$ & 3 & $100 \%$ & 96 & $94 \%$ \\
\hline Ind. CTX > CTXRT & 4 & $100 \%$ & 47 & $93 \%$ \\
\hline
\end{tabular}

XRT - Radiotherapy; CTXRT - concurrent chemoradiation; Ind. CTX - Induction chemotherapy.

Seventy-one (10\%) patients who were recurrence free died of other causes. Death in these patients was associated $(\mathrm{p}<.01)$ with pack-years, as the 5 -year survival rates for recurrence-free patients who were never smokers, smoked 1-30 pack-years and smoked $>30$ pack-years were $95 \%, 95 \%$ and $83 \%$, respectively.

\section{Discussion}

The management of oropharyngeal cancer continues to evolve with new developments in biology, technology, and clinical trials. Our current series describes a cohort of over 1000 patients with stage 3 and 4 oropharynx cancer treated over the past decade. High rates of disease control were achieved overall, though analysis of variables suggests a range of prognoses dependent principally on factors at presentation, which likely reflect the HPV status of these cancers [12]. However, it appears that treatment factors also influence outcomes, including the use of IMRT and chemotherapy in certain subgroups.

HPV status has recently been recognized as a major prognostic factor in outcomes of patients with oropharynx cancer [13]. However, the patients in our cohort were treated prior to routine testing for HPV (and p16), and retrospective pathologic review of over 1000 samples, many of which are from outside institutions was impractical for this review, and likely to result in a large amount of missing data points.

Our cohort did consist of 423 never smokers, and it is recognized that the vast majority of patients who are never smokers present with HPV positive tumors [25]. The 5-year local-regional control rate for these never smokers was $92 \%$ consistent with other reports on outcomes of HPV positive tumors. Without HPV status, it is more challenging to assess outcomes in HPV negative patients from our data, particularly since any history of tobacco exposure may confound the outcome of patients regardless of HPV status. Former smokers appeared to have similar outcomes to never smokers. This may be due to this cohort having a lesser intensity of smoking, but also, as noted recently by RTOG, [25] there is a greater percentage of HPV-positive tumors among former smokers, compared with current smokers.
Based on our past experiences, our general philosophy has been to use a risk-based approach that principally incorporates staging into our management algorithms. Historically our irradiated oropharyngeal cancer patients with T1 -2 disease had high rates of local control, $[17,26,27]$ and patients who were node positive had high rates of regional control [28]. Thus, our decision to treat patients with concurrent chemoradiation was principally reserved for those patients with bulky primary disease (T3-4). Using this approach, we observed a clear benefit for our patients with T3-4 disease treated with concurrent chemoradiation. However, despite more intensive therapy based on T-category, primary tumor size and extent remained a strong prognostic factor. Regardless of smoking status, patients with more advanced disease had a greater probability of local recurrence. More advanced T-category was also associated with a higher likelihood of distant recurrence and poorer survival.

Despite the absence of HPV stratification, our 357 patients with T1-2 disease treated with radiation without concurrent chemotherapy had 95\% and 90\% 5-year local regional control and overall survival rates. Current guidelines favor concurrent therapy for all stage 3 and 4 patients. The evidence for this strategy, is robust, but based on numerous studies that included patients with the most advanced disease. Particularly for patients with T1 disease, data is sparse, as few randomized trials evaluating the role of concurrent therapy included patients with low volume disease [4]. The RTOG, for example, has excluded patients with $\mathrm{T} 1$ disease in their definitive trials of locally advanced head and neck cancer $[2,13,21,22]$. Prior to the routine use of chemotherapy for head and neck cancer, many had been critical of the AJCC and UICC stage grouping [29]; in particular these studies have demonstrated more favorable prognoses for patients with T1 node positive disease compared with other patients staged 3-4A. Thus, particularly for T1 staged patients (who typically represent about onethird of the oropharyngeal carcinoma population) we continue to favor radiation alone.

We could not demonstrate a benefit in outcome for patients treated with induction therapy, but as described above, the rates of distant disease have decreased suggesting a benefit at least compared to historical controls. 
Several years ago we reported on a cohort of node positive oropharyngeal carcinoma patients treated with radiation only [17]. These 299 patients had T1-2 disease and were treated without systemic therapy. In that report, the overall distant recurrence rate in patients with local regional control was $17 \%$, compared with $11 \%$ for the entire current cohort here, and 7\% for those staged T1-2. This observation is despite the current cohort having a higher percentage of patients staged $\mathrm{N} 2 \mathrm{~b}$ or greater, but is consistent with other recent reports of outcomes of patients treated with chemo-radiation for oropharyngeal cancer. Two principal differences between our earlier experience and the current series are that a greater percent of patients in the current series are likely HPV positive and the greater use of chemotherapy in the current experience. As many series describe similarities in distant metastases rates between HPV positive and negative patients $[13,14]$, greater credence is given to the second hypothesis that chemotherapy likely impacted outcomes favorably.

The retrospective nature of this study prohibits category 1 based-evidence, and retrospective studies are commonly critiqued for inherent biases. We believe the magnitude of the cohort size obviates some of the concerns regarding the inferiority of a retrospective study. In particular, all 1046 patients were treated with radiation schedules designed for curative intent. Only 8 patients $(<1 \%)$ were excluded for being treated with palliative radiation schedules, and while the patient population was extracted from a database of irradiated patients, it was extremely rare for our multidisciplinary team to treat patients without radiation.

While MDACC is a tertiary cancer center, the population presented here is likely as representative of the general population presenting with oropharynx cancer. We did not include a comorbidity index of our patients, but the population did include patients who had comorbidities that sometimes either precluded the use of cisplatin, the drug with the strongest evidence of efficacy, or chemotherapy in general, thus including patients often excluded in phase 3 trials. Comorbidities, combined with biases of patients and individuals within a large multidisciplinary team impacted ultimate treatment decisions, and help explain that while we used a risk-based approach, still some of our patients with T1 category received chemotherapy, while $10 \%$ of our patients with T4-category did not receive chemotherapy.

We also chose a relatively narrow time frame (2000 2007) for this study, though going further back in time would have allowed us to expand the cohort significantly. This decision was made as we wanted to establish a robust trial with adequate follow-up (median, 58 months), but still reflect on modern treatment paradigms. Despite this goal, our series had great heterogeneity of therapy which reflects on the controversies of management for this disease. The last 2 decades saw great interest in treatment intensification to improve outcomes which ironically coincided with the increase in HPV related disease which has been demonstrated to be more chemotherapy and radiation sensitive [13-15,30]. Thus some patients were treated with chemotherapy doublets and radiation, while others received altered radiation fractionation. Favorable reports on taxane based induction regimens [5] led to an increased use of neoadjuvant chemotherapy, particularly for our patients with advanced nodal disease, though we frequently eliminated concurrent chemotherapy in these patients. Additionally, we often did not use chemotherapy in patients with small tumor burden despite having 'advanced-staged' disease. Radiation strategies changed, and we integrated more conformal radiation into our practice through the use of IMRT, and increased our use of ipsilateral radiation for selected patients with tonsillar cancer [31]. Even with this heterogeneity of patients and treatments, we report high rates of disease control and survival.

In conclusion, we describe a cohort of over 1000 oropharyngeal cancer patients with stage $3-4 \mathrm{~B}$ disease irradiated over an 8 year period. These patients were treated in an era in which chemotherapy was becoming well integrated into the management of advanced head and neck cancer, and IMRT developed into the routine form of radiation planning and delivery. While several trials have demonstrated HPV positivity is associated with improved prognosis, we believe T-category, a classic "biomarker" remains paramount in treatment decision-making. Thus we still advocate radiation alone often as therapy for patients with low volume disease despite nominally being categorized as having stage 3 or 4 disease. We also caution against treatment deintensification for patients with T4 disease, even if biomarkers such as HPV status suggest a more favorable prognosis. While smoking status is not a consistent surrogate for HPV status, it is clear that never smokers have excellent outcomes. Furthermore, current smokers should be strongly encouraged, counseled, and treated for cessation as an important augmentation to the principal cancer treatment.

\section{Competing interests \\ The authors declare that they have no competing interests.}

\section{Authors' contributions}

AG participated in the study design, recorded patient data, performed the statistical analysis and drafted the manuscript. MK, WM, RW, SF, KA, DR and EM participated in the acquisition of patient data and in drafting the manuscript. GG and BB participated in the drafting of the manuscript. All authors read and approved the final manuscript.

\section{Author details}

${ }^{1}$ Department of Radiation Oncology, University of Texas M.D. Anderson Cancer Center, 1515 Holcombe Blvd, Houston, TX 77030, USA. ²Department of Thoracic/Head and Neck Medicine, University of Texas M. D. Anderson Cancer Center, 1515 Holcombe Blvd, Houston, TX 77030, USA. ${ }^{3}$ Department of Head and Neck Surgery, University of Texas M. D. Anderson Cancer Center, 1515 Holcombe Blvd, Houston, TX 77030, USA. ${ }^{4}$ Department of Epidemiology, University of Texas M.D. Anderson Cancer Center, 1515 Holcombe Blvd, Houston, TX 77030, USA. 
Received: 16 November 2012 Accepted: 20 January 2013

Published: 29 January 2013

\section{References}

1. Bourhis J, Overgaard J, Audry H, et al: Hyperfractionated or accelerated radiotherapy in head and neck cancer: a meta-analysis. Lancet 2006, 368:843-854.

2. Fu KK, Pajak TF, Trotti A, et al: A Radiation Therapy Oncology Group (RTOG) phase III randomized study to compare hyperfractionation and two variants of accelerated fractionation to standard fractionation radiotherapy for head and neck squamous cell carcinomas: first report of RTOG 9003. Int J Radiat Oncol Biol Phys 2000, 48:7-16.

3. Overgaard J, Hansen $H$, Specht $L$, et al: Five compared with six fractions per week of conventional radiotherapy of squamous-cell carcinoma of head and neck: DAHANCA 6 and 7 randomised controlled trial. Lancet 2003, 362:933-940.

4. Pignon JP, le Maitre A, Maillard E, Bourhis J: Meta-analysis of chemotherapy in head and neck cancer (MACH-NC): an update on 93 randomised trials and 17,346 patients. Radiother Oncol 2009, 92:4-14.

5. Posner MR, Hershock DM, Blajman CR, et al: Cisplatin and fluorouracil alone or with docetaxel in head and neck cancer. N Engl J Med 2007, 357:1705-1715.

6. Chao K, Ozyigit G, Blanco A, et al: Intensity-modulated radiation therapy for oropharyngeal carcinoma: impact of tumor volume. Int J Radiat Oncol Biol Phys 2004, 59:43-50.

7. Eisbruch $A$ : Intensity-modulated radiotherapy of head-and-neck cancer: encouraging early results. Int J Radiat Oncol Biol Phys 2002, 53:1-3.

8. Eisbruch A, Harris J, Garden AS, et al: Multi-institutional trial of accelerated hypofractionated intensity-modulated radiation therapy for early-stage oropharyngeal cancer (RTOG 00-22). Int J Radiat Oncol Biol Phys 2009, 76:1333-1338

9. Guadagnolo BA, Liu CC, Cormier JN, Du XL: Evaluation of trends in the use of intensity-modulated radiotherapy for head and neck cancer from 2000 through 2005: socioeconomic disparity and geographic variation in a large population-based cohort. Cancer 2010, 116:3505-3512.

10. Chaturvedi AK, Engels EA, Anderson WF, Gillison ML: Incidence trends for human papillomavirus-related and -unrelated oral squamous cell carcinomas in the united states. J Clin Oncol 2008, 26:612-619.

11. D'Souza G, Kreimer AR, Viscidi R, et al: Case-control study of human papillomavirus and oropharyngeal cancer. N Engl J Med 2007, 356:1944-1956.

12. Sturgis EM, Ang KK: The epidemic of HPV-associated oropharyngeal cancer is here: is it time to change our treatment paradigms? J Nat/ Compr Canc Netw 2011, 9:665-673.

13. Ang KK, Harris J, Wheeler $R$, et al: Human papillomavirus and survival of patients with oropharyngeal cancer. N Engl J Med 2010, 363:24-35.

14. Rischin D, Young RJ, Fisher R, et al: Prognostic significance of p16INK4A and human papillomavirus in patients with oropharyngeal cancer treated on TROG 02.02 phase III trial. J Clin Oncol 2010, 28:4142-4148.

15. Shi W, Kato H, Perez-Ordonez B, et al: Comparative prognostic value of HPV16 E6 mRNA compared with in situ hybridization for human oropharyngeal squamous carcinoma. J Clin Oncol 2009, 27:6213-6221.

16. Kies MS, Holsinger FC, Lee JJ, et al: Induction chemotherapy and cetuximab for locally advanced squamous cell carcinoma of the head and neck: results from a phase II prospective trial. J Clin Oncol 2010, 28:8-14.

17. Garden AS, Asper JA, Morrison WH, et al: Is concurrent chemoradiation the treatment of choice for all patients with Stage III or IV head and neck carcinoma? Cancer 2004, 100:1171-1178.

18. Pytynia KB, Grant JR, Etzel CJ, Roberts DB, Wei Q, Sturgis EM: Matched-pair analysis of survival of never smokers and ever smokers with squamous cell carcinoma of the head and neck. J Clin Oncol 2004, 22:3981-3988.

19. American Joint Committee on Cancer Staging: Manual for staging of cancer. Philadelphia: J. B. Lippincott; 2002

20. Thariat J, Ang KK, Allen PK, et al: Prediction of neck dissection requirement after definitive radiotherapy for head-and-neck squamous cell carcinoma. Int J Radiat Oncol Biol Phys 2011, 82:e367-374.

21. Garden AS, Harris J, Trotti A, et al: Long-term results of concomitant boost radiation plus concurrent cisplatin for advanced head and neck carcinomas: a phase II trial of the radiation therapy oncology group (RTOG 99-14). Int J Radiat Oncol Biol Phys 2008, 71:1351-1355.
22. Ang KK, Zhang QE, Rosenthal DI, et al: A randomized phase III trial (RTOG 0522) of concurrent accelerated radiation plus cisplatin with or without cetuximab for stage III-IV head and neck squamous cell carcinomas (HNC). J Clin Oncol 2011, 29(suppl):5500.

23. Bonner JA, Harari PM, Giralt J, et al: Radiotherapy plus cetuximab for squamous-cell carcinoma of the head and neck. N Engl J Med 2006, 354:567-578.

24. Tsao AS, Garden AS, Kies MS, et al: Phase I/II study of docetaxel, cisplatin and concomitant boost radiation for locally advanced squamous cell cancer of the head and neck. J Clin Oncol 2006, 24:4163-4169.

25. Gillison ML, Zhang $\mathrm{Q}$, Jordan $\mathrm{R}$, et al: Tobacco smoking and increased risk of death and progression for patients with p16-positive and p16-negative oropharyngeal cancer. J Clin Oncol 2012, 30:2102-2111.

26. Gwozdz JT, Morrison WH, Garden AS, Weber RS, Ang KK, Peters LJ: Concomitant boost radiotherapy for squamous carcinoma of the tonsillar fossa. Int J Radiat Oncol Biol Phys 1997, 39:125-135.

27. Mak AC, Morrison WH, Garden AS, Ang KK, Goepfert H, Peters LJ: Base-oftongue carcinoma: treatment results using concomitant boost radiotherapy. Int J Radiat Oncol Biol Phys 1995, 33:289-296.

28. Peters LJ, Weber RS, Morrison WH, Byers RM, Garden AS, Goepfert H: Neck surgery in patients with primary oropharyngeal cancer treated by radiotherapy. Head Neck 1996, 18:552-559.

29. Groome P, Schulze K, Mackillop W, et al: A comparison of published head and neck stage groupings in carcinomas of the tonsillar region. Cancer 2001, 92:1484-1494.

30. Fakhry C, Westra WH, Li S, et al: Improved survival of patients with human papillomavirus-positive head and neck squamous cell carcinoma in a prospective clinical trial. J Natl Cancer Inst 2008, 100:261-269.

31. Chronowski GM, Garden AS, Morrison WH, et al: Unilateral radiotherapy for the treatment of tonsil cancer. Int J Radiat Oncol Biol Phys 2012, 83:204-209.

doi:10.1186/1748-717X-8-21

Cite this article as: Garden et al:: Outcomes and patterns of care of patients with locally advanced oropharyngeal carcinoma treated in the early $21^{\text {st }}$ century. Radiation Oncology 2013 8:21.

\section{Submit your next manuscript to BioMed Central and take full advantage of:}

- Convenient online submission

- Thorough peer review

- No space constraints or color figure charges

- Immediate publication on acceptance

- Inclusion in PubMed, CAS, Scopus and Google Scholar

- Research which is freely available for redistribution
C BioMed Central 